\title{
BMJ Global Health Geospatial mapping of access to timely essential surgery in sub-Saharan Africa
}

\author{
Sabrina Juran, ${ }^{1,2}$ P. Niclas Broer, ${ }^{3}$ Stefanie J. Klug, ${ }^{2}$ Rachel C. Snow, ${ }^{1}$ \\ Emelda A. Okiro, ${ }^{4}$ Paul O. Ouma, ${ }^{4}$ Robert W. Snow, ${ }^{4}$ Andrew J. Tatem, ${ }^{5,6}$ \\ John G. Meara, ${ }^{7}$ Victor A. Alegana ${ }^{5,6}$
}

To cite: Juran S, Broer PN, Klug SJ., et al. Geospatial mapping of access to timely essential surgery in subSaharan Africa. BMJ Glob Health 2018;3:e000875. doi:10.1136/ bmjgh-2018-000875

Handling editor Seye Abimbola

Received 11 April 2018

Revised 4 July 2018

Accepted 6 July 2018

\section{Check for updates}

C) Author(s) (or their employer(s)) 2018. Re-use permitted under CC BY-NC. No commercial re-use. See rights and permissions. Published by BMJ.

${ }^{1}$ United Nations Population Fund Technical Division, Population and Development Branch, New York City, New York, USA

${ }^{2}$ Lehrstuhl für Epidemiologie, Technische Universität

München, München, Germany

${ }^{3}$ Klinikum Bogenhausen,

Städtisches Klinikum München,

Technische Universität

München, München, Germany

${ }^{4}$ Kenya Medical Research

Institute/Wellcome Trust

Research Programme, Nairobi,

Kenya

${ }^{5}$ WorldPop, Geography and

Environment, University of

Southampton, Southampton, UK

${ }^{6}$ Flowminder Foundation,

Stockholm, Sweden

${ }^{7}$ Program in Global Surgery and Social Change, Harvard Medical School, Boston, Massachusetts, USA

Correspondence to

Dr. Sabrina Juran;

sabrinajuran@gmail.com

\section{ABSTRACT}

Introduction Despite an estimated one-third of the global burden of disease being surgical, only limited estimates of accessibility to surgical treatment in sub-Saharan Africa exist and these remain spatially undefined. Geographical metrics of access to major hospitals were estimated based on travel time. Estimates were then used to assess need for surgery at country level.

Methods Major district and regional hospitals were assumed to have capability to perform bellwether procedures. Geographical locations of hospitals in relation to the population in the 47 sub-Saharan countries were combined with spatial ancillary data on roads, elevation, land use or land cover to estimate travel-time metrics of $30 \mathrm{~min}, 1$ hour and 2 hours. Hospital catchment was defined as population residing in areas less than 2 hours of travel time to the next major hospital. Travel-time metrics were combined with fine-scale population maps to define burden of surgery at hospital catchment level.

Results Overall, the majority of the population (92.5\%) in sub-Saharan Africa reside in areas within 2 hours of a major hospital catchment defined based on spatially defined travel times. The burden of surgery in all-age population was 257.8 million to 294.7 million people and was highest in high-population density countries and lowest in sparsely populated or smaller countries. The estimated burden in children $<15$ years was 115.3 million to 131.8 million and had similar spatial distribution to the all-age pattern.

Conclusion The study provides an assessment of accessibility and burden of surgical disease in subSaharan Africa. Yet given the optimistic assumption of adequare surgical capability of major hospitals, the true burden of surgical disease is expected to be much greater. In-depth health facility assessments are needed to define infrastructure, personnel and medicine supply for delivering timely and safe affordable surgery to further inform the analysis.

\section{INTRODUCTION}

In the report 'Global Surgery 2030: Evidence and Solutions for Achieving Health, Welfare, and Economic Development', the Lancet Commission on Global Surgery (LCoGS) highlighted that 5 billion people globally do not have access to safe, affordable surgical and anaesthesia care. ${ }^{1}$ It is estimated that approximately one-third

\section{Key questions}

What is already known?

- An estimated 5 billion people do not have access to basic, safe surgical care.

- The proportion of the population that can access, within 2 hours, a health facility with capacity to perform caesarean delivery, laparotomy and treatment of open fracture (the bellwether procedures) is unknown in sub-Saharan Africa.

\section{What are the new findings?}

- The majority of the population in sub-Saharan Africa resided in areas within 2 hours of a major hospital that could theoretically carry out the bellwether procedures.

- The estimated need for surgery in sub-Saharan Africa lies between 257.8 million and 294.7 million people.

- The estimated burden in children under 15 years was 115.3 million to 131.8 million and had similar spatial distribution to the all-age pattern.

What do the new findings imply?

- Sub-Saharan countries need to overcome barriers of access to safe surgery to reduce negative outcomes such as deaths.

of the global burden of disease constitutes surgical disease. ${ }^{2}{ }^{3}$ Surgical disease encompasses any illness where outcomes can be improved through surgical care. ${ }^{14}$ Inequality in surgical care is distinctive; of the 313 million estimated global surgical procedures undertaken each year, only 6\% were estimated to occur in low/middle-income countries (LMICs). ${ }^{5}$ This disparity is, however, contributed by lack of quantity and quality data on surgery in these countries. Untreated, many surgical conditions are a source of lifetime disability and can cause premature mortality estimated at 16.9 million in $2010 .^{6-8}$

For a long time, surgery has not been included in the discussion on how to improve global healthcare and strengthen health systems, especially in the most remote regions 
of the world. Only in 2008 did surgery become the focus of attention when it was called the 'forgotten stepchild of global health'. Today, there is an increasing awareness to include surgical care as part of a wider strategy for improving universal healthcare delivery globally. ${ }^{8-11}$ Systematic reviews suggest that surgery is as cost-effective in LMICs as other health interventions, for example, oral rehydration therapy, vitamin A supplementation or antiretroviral therapy promotion. ${ }^{12} 13$

Physical accessibility, including distance to hospitals, availability and cost of transportation; poor state of roads and infrastructure as well as geographic conditions, are important factors that determine whether a patient seeks care and health outcomes in these settings. ${ }^{1}$ In 2015 , the Lancet Commission ${ }^{1}$ recommended measuring access to timely surgical care (indicator 1 on percentage of population within 2 hours of access) as part of six indicators that measure a healthcare system's ability to provide safe surgery. The other five indicators include: the number of specialist surgical providers (surgeons, anaesthetists and obstetricians) per 100000 population, the number of surgical procedures per 100000 population, perioperative mortality rates, risk of impoverishing expenditure when surgery is required, and risk of catastrophic expenditure when surgery is required.

There have been a few studies that assessed these indicators since 2015, when the Lancet commission report was released. An attempt has been made to define global estimates on surgeons, anaesthesiologists and obstetricians ${ }^{14}{ }^{15}$; surgical volumes ${ }^{4}{ }^{16}$; financial burden on surgery $^{17}$; and perioperative mortality. ${ }^{18}{ }^{19}$ While there are major gaps in surgical access across sub-Saharan Africa (SSA), understanding these gaps would support global and country-level decision-makers to plan and programme for improvements. Regarding indicator 1, Alkire et al's study ${ }^{20}$ used country-level data to measure timeliness based on the proportion of serious injuries transported by an ambulance. Provision of ambulatory and emergency services is low in SSA. ${ }^{21} 22$

Further, data on hospital capacity to perform surgery in SSA are not always available without an independent facility assessment at country level. For example, Esquivel et al mapped access to safe, timely and essential surgical care in Zambia ${ }^{23}$ and estimated that $15 \%$ of the population lived in areas that were outside of the 2-hour threshold of distance to a hospital with surgical capacity, regardless of its human resource capacity or infrastructure. Another assessment showed that only $34 \%$ of the population was within 2 hours of a hospital with capacity to perform safe surgery while adhering to guidelines by the WHO. ${ }^{24}$ Barriers to accessibility to surgical services have been predicated based on several factors, including geographic proximity, cost and safety. ${ }^{20}$ There has been evidence that greater physical distance or travel time (eg, $>1$ hour) impacts health outcomes before and after surgery. 2526

The recent publications of hospital locations in relation to emergency care ${ }^{2527}$ provide a platform for assessing indicator 1 from the Lancet commission for countries in SSA. The aim was to provide first-stage estimates of indicator 1 by measuring access to major hospitals for all of SSA based on these hospital locations. This objective has been undertaken in the present study in 47 countries. The secondary objectives were to assess the population dropout rate at $30 \mathrm{~min}$ and 1 hour of a hospital as well to estimate the need for surgery in children under the age of 14 based on estimated catchment populations.

\section{METHODS \\ Health facilities/hospitals' data}

In an effort to understand distribution and provision of emergency services in SSA, an inventory of public hospitals was conducted elsewhere, and data on their locations are now available publicly. ${ }^{28}$ These data ${ }^{29}$ were assembled mainly from national governments (ministries of health and statistical agencies), regional WHO websites, Demographic and Health Survey (DHS) Service Provisional Assessment (SPA), United Nations Office for Humanitarian Country Assistance data exchange portal (https:/ / data.humdata.org/group) and other publicly available lists from international organisations such as the Unicef. From this list we compiled a dataset of major regional and district-level hospitals $(n=4900)$ to conduct a firststage estimate of indicator 1 by measuring access to major hospitals for all of SSA. ${ }^{28}$ An underlying assumption of the present study is that these major regional and district hospitals can provide all three basic surgical procedures, that is, bellwether procedures (laparotomy, caesarean section and treatment of an open fracture). ${ }^{1623} 30$ Only a baseline assessment of all hospitals in a given country using, for example, the WHO surgical assessment toolkit ${ }^{31}$ would provide the detail needed to validate this assumption.

The majority of the hospitals assessed in the study were managed by local governments $(86 \%)$ independently, while the remaining $14 \%$ were managed by non-governmental organisations or faith-based institutions. The listing excluded private-for-profit facilities or specialised hospitals, which may provide basic surgical care but were difficult to audit at a national level. Just over half (54\%) of these hospitals were georeferenced using global positioning system (GPS) receivers. For those that had not been georeferenced, coordinates were derived by address geocoding of place names from web-based geodatabases and Google Earth. ${ }^{32}$ Online supplementary figure S1 shows sub-Saharan hospital locations.

\section{Spatial ancillary data and population}

A spatial dataset of roads in SSA was assembled from OpenStreetMap (OSM, 2017). In this analysis, only roads classified as a motorway, primary or secondary were included. To allow for a consistent comparison, we excluded lower-tier roads (tertiary roads, streets, link roads and footpaths) due to uncertainty of their completeness across countries. Motorised transport was, 
therefore, used in the analysis of travel times along the major roads.

A land cover map from Medium Resolution Imaging Spectrometer GlobCover product (http://ionial.esrin. esa.int $/)^{33}$ at a $300 \mathrm{~m}$ spatial resolution for SSA was used to demarcate all other topographical characteristics (ie, the land use or land cover classifications). Digital elevation data (topography) was downloaded from the National Aeronautics and Space Administration's Shuttle Radar Topography Mission (SRTM) (https://www2.jpl. nasa.gov/srtm/). SRTM has a spatial resolution of $90 \mathrm{~m}$ approximately at the equator and is archived using $5^{\circ}$ by $5^{\circ}$ tiles.

Lastly, age-structured maps of population distribution were downloaded from WorldPop (www.worldpop. org) ${ }^{34}$ including 2015 estimates of all-age population and children under the age of 15 years. The methodology for modelling population is described elsewhere ${ }^{35}$ and combines data from various population and housing censuses and human settlements using machine learning approaches to generate a gridded prediction of population density at $100 \mathrm{~m}$ spatial resolution approximately. ${ }^{35}$ For this analysis, the population data and all raster layers were resampled to a spatial resolution of $1 \mathrm{~km}$ by $1 \mathrm{~km}$.

\section{Developing gridded layers of travel times to hospitals in SSA and zoning hospital catchments}

A bimodal model that include walking across land cover and motorised travel along major roads was built in AccessMod version 5 software to generate a raster surface of travel times to the hospital location. ${ }^{36}$ This platform has been used in many studies deriving travel times. ${ }^{36-39}$ First, 23 classifications for broad land use or land cover in GlobCover were reduced to six major classes of crop cover, forest, grassland, urban areas, bare ground and permanent water or snow. Second, a secondary land cover map was created by combining the broad six land use or land cover classification with the major roads. An anisotropic analysis was used to allow influence of slope on travel speed. Travel speed (impedance) was then assigned to the seven resulting classes $(80 \mathrm{~km} /$ hour $)$ for a major road with motorised travel, $4 \mathrm{~km} /$ hour with walking correction on vegetation patches, $30 \mathrm{~km} /$ hour for urban areas, and for desert landscapes, a $2 \mathrm{~km} /$ hour speed was used. ${ }^{36}$ The algorithm for deriving travel time in each class included a slope correction derived from elevation data with travel speeds calculated for each degree rise of slope based on Tobler's equation ( $V=6^{*} \exp (-3.5 \mathrm{abs}$ [Tan (slope in degrees $/ 57.296)+0.05]),{ }^{40}$ where $V$ is the calculated speed. Hence, on flat terrain, the walking pace is about $5.0 \mathrm{~km} /$ hour while for a $20^{\circ}$ rise in slope, the pace is lower $(1.4 \mathrm{~km} /$ hour $)$.

Catchment areas (hard boundary) were defined from the gridded travel times within which people should have access to a healthcare facility capable of essential safe surgical and anaesthesia care within 2 hours, 1 hour and $30 \mathrm{~min}$. To estimate the size of hospital catchment, a mean radius for these catchment zones was calculated. From previous literature, these thresholds have been used as proxies for emergency services ( 30 min to 1 hour), acute inpatient services (1 hour to 2 hours) and specialty services (2 hours). ${ }^{41}$ The 2-hour cut-off was used to align with evidence related to time between onset of bleeding and death if medical intervention is not received. ${ }^{42}$ The use of the 2-hour time frame does not suggest that all surgical conditions need to be treated within this period. The critical window for morbidity and mortality may be shorter or longer than 2 hours, depending on the medical condition. For example, surgery to treat a ruptured uterus must be secured within 2 hours to avoid death due to haemorrhage, whereas surgery to treat cataracts is not as time sensitive; however, for all conditions, proximity to surgical care may impact whether a patient accesses. Additional bands of travel within $30 \mathrm{~min}$ and 1 hour were also derived. Population needing surgery was estimated based on aggregated population within $30 \mathrm{~min}$, 1 hour and 2 hours of a hospital.

\section{Estimating the need for surgery in SSA}

The need for surgery at the population level was estimated based on aggregated populations within $30 \mathrm{~min}$, 1 hour and 2 hours of a hospital with assumed surgical capacity at the subnational level. The sum of the population was multiplied by the estimated constant rate of burden of surgical disease from previous studies. ${ }^{2}$ To estimate the surgical burden of disease relating to deaths or disability-adjusted life years, a lower proportion estimate of 0.28 and the upper proportion estimate of 0.32 was used following Shrime et al (2015). ${ }^{2}$

\section{RESULTS}

\section{Accessibility to surgery in SSA for all-age population}

On average, there were 0.5 regional or district hospitals per 100000 population. The largest hospital to population ratio per 100000 population was in geographically smaller or sparsely populated countries such as Djibouti, Namibia, Botswana or Small Island states such as Sao Tome and Principe.

Figure 1A-C show the proportion of the population at administrative level 1 within the catchment area of 2 hours of a hospital with the assumed capacity to provide surgery. The violin plot shows regional variations for Central Africa, East and Horn of Africa, Southern Africa and West Africa. Table 1 and table 2 show regional and country level summary of population estimates for the three classifications of travel times (<30 min, 1 hour and 2 hours), respectively. The absolute number of people within each administrative level within the catchment area of 2 hours are shown in figure 2A-C.

First, there was regional variation in estimate of population within $30 \mathrm{~min}, 1$ hour and 2 hours of a major hospital with surgical capacity as shown by the violin plot. 

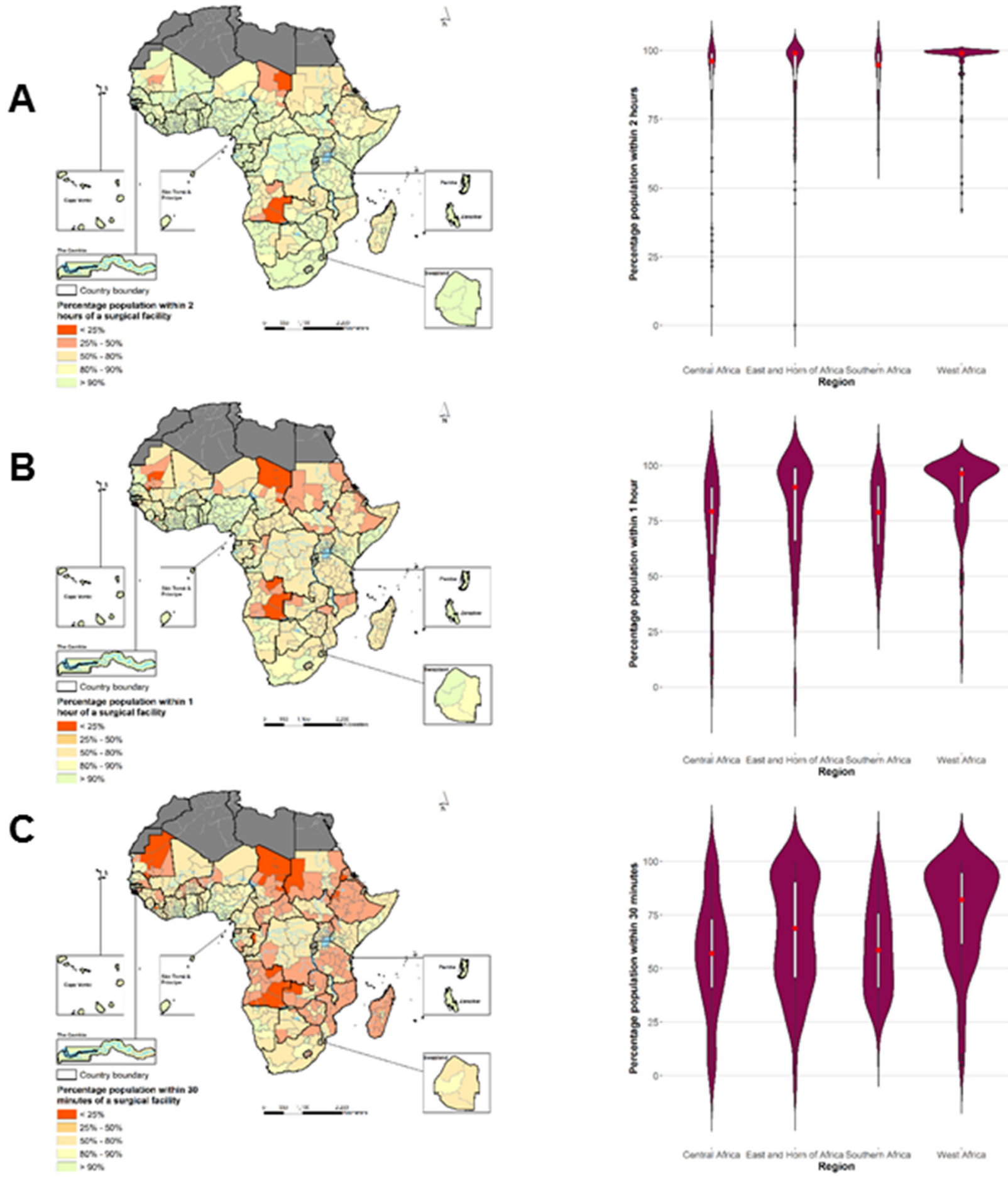

Figure 1 Percentage of population by administrative level 1 in sub-Saharan Africa with access to major surgical facility.

For example, at $30 \mathrm{~min}$, the median proportion of population within a major hospital was $56 \%$ in central Africa compared with $75 \%$ in West Africa. There were further differences at a national and subnational levels. In Zambia, our estimates suggest that $86 \%$ of all-age population was within 2 hours of a major hospital but that reduced to $66 \%$ and $49 \%$ for 1 hour and $30 \mathrm{~min}$, respectively. In contrast, in Ethiopia a country with significantly higher population, $79 \%$ were within 2 hours and that reduced to $61 \%$ and $42 \%$ for 1 hour and $30 \mathrm{~min}$, respectively.
While there was a variation in access at administrative 1 level (figure 1C), most of the all-age population (>55\%) in Angola, Chad, Eritrea, the Sudan, Zambia, Ethiopia, Madagascar and Mozambique lived in areas greater than 30 min of the nearest hospital assumed to have the capability to perform basic surgical bellwether procedure.

Overall from figure $1 \mathrm{~A}, 92.5 \%$ of the population in SSA resided in areas within 2 hours of a hospital with surgical capability, assuming that these hospitals had the adequate infrastructure and workforce. 
Table 1 Regional level estimates of all-age population within travel time of $30 \mathrm{~min}$, 1 hour and 2 hours (catchment) of surgery at a national level in sub-Saharan Africa

\begin{tabular}{|c|c|c|c|c|c|c|c|c|c|}
\hline Region & $\begin{array}{l}\text { Estimated } \\
2015 \\
\text { population } \\
\text { (in millions) }\end{array}$ & $\begin{array}{l}\text { No of } \\
\text { hospitals } \\
\text { with } \\
\text { potential } \\
\text { surgical } \\
\text { capacity }\end{array}$ & $\begin{array}{l}\text { Hospital to } \\
\text { population } \\
\text { ratio per } \\
100000 \\
\text { population }\end{array}$ & $\begin{array}{l}\text { Percentage } \\
\text { of (mean) } \\
\text { people } \\
30 \text { min of } \\
\text { a surgical } \\
\text { facility }\end{array}$ & $\begin{array}{l}\text { Percentage } \\
\text { of (mean) } \\
\text { people } \\
1 \text { hour of } \\
\text { a surgical } \\
\text { facility }\end{array}$ & $\begin{array}{l}\text { Percentage } \\
\text { of (mean) } \\
\text { people } \\
2 \text { hours of } \\
\text { a surgical } \\
\text { facility }\end{array}$ & $\begin{array}{l}\text { Proportion } \\
\text { of children } \\
\text { under } \\
15 \text { years }\end{array}$ & $\begin{array}{l}\text { Proportion } \\
\text { of women of } \\
\text { childbearing } \\
\text { age }\end{array}$ & $\begin{array}{l}\text { Estimated burden } \\
\text { of surgery in all- } \\
\text { age population (in } \\
\text { millions) outside of } \\
2 \text { hours catchment } \\
\text { (mean in millions) }\end{array}$ \\
\hline $\begin{array}{l}\text { Central } \\
\text { Africa }\end{array}$ & 151.55 & 971 & 0.64 & 56.99 & 72.62 & 87.34 & 0.47 & 0.22 & 19.19 \\
\hline $\begin{array}{l}\text { Eastern } \\
\text { Africa* }^{*}\end{array}$ & 329.14 & 1417 & 0.43 & 66.41 & 80.77 & 90.75 & 0.45 & 0.23 & 30.45 \\
\hline $\begin{array}{l}\text { Southern } \\
\text { Africa }\end{array}$ & 163.47 & 920 & 0.56 & 60.07 & 76.13 & 91.20 & 0.40 & 0.24 & 14.39 \\
\hline $\begin{array}{l}\text { Western } \\
\text { Africa }\end{array}$ & 352.72 & 1597 & 0.45 & 75.88 & 88.48 & 96.11 & 0.45 & 0.23 & 13.72 \\
\hline
\end{tabular}

*Eastern African countries include the countries of the Horn of Africa.

\section{Estimated burden of surgery relative to geographic proximity in SSA}

By assuming that all the population within catchment area to major hospitals was at risk of surgical disease, the estimated burden of surgery was between 257.8 million people (lower estimate) and 294.7 million people (upper estimate) of all ages within 2 hours of travel time (figure 2A-C). This, however, declined to 187.2 million213.9 million based on the $30 \mathrm{~min}$ catchment and 227.8 million-260.3 million people based on the 1-hour cut-off. At a national level, these estimates were highest in countries with high-population density such as the Sudan, the Democratic Republic of Congo (DRC), Ethiopia, Nigeria and in Tanzania and lowest in sparsely populated and geographically smaller countries or islands including Swaziland, Djibouti, Sao Tome and Principe, and Cape Verde. From table 1, the burden in all-age population within 2 hours of a hospital was 3.9 million to 4.5 million people in Zambia, 1.2 million to 1.4 million people in Liberia and 3.2 million to 3.7 million people in Rwanda. In 2015, 42\% of SSA's population was under the age of 15 years, and there were 1.2 billion young people between the age of 15 and 24 years. For children ( $<15$ years), an estimated burden was 115.3 million to 131.8 million children based on a 2-hour catchment and 82.9 million to 94.77 million children based on $30 \mathrm{~min}$ travel time to a hospital with surgical capacity.

\section{Accessibility to surgery for children under $\mathbf{1 5}$ years}

Of the total population in SSA in 2015, 432.4million $(43.2 \%)$ were children under the age of 15 years (table 1$)$. Of these, 414.8 million $(95.9 \%)$ were estimated to be within the 2-hour catchment of a surgical hospital. In most countries, except for two (Angola and Eritrea), over $80 \%$ of all children were within 2 hours of a major surgical hospital. However, the number of children within catchment of a major regional or district hospital reduced significantly when estimating catchment within the $30 \mathrm{~min}$ travel time to approximately 295.8 million $(68.4 \%)$. While the proportion of children residing in areas within 30 min of a facility with surgical capacity was greater than $80 \%$ in at least 12 countries, that proportion was $50 \%$ or less in 11 countries (Angola, Chad, Eritrea, Ethiopia, Lesotho, Madagascar, Mauritania, Mozambique, South Sudan, the Sudan and Zambia).

\section{DISCUSSION}

This study evaluated geographic accessibility to essential surgery and estimated the burden of surgery in SSA based on regional and district level hospitals with the potential capacity to perform bellwether procedures. Travel times to a hospital adjusting for mode of travel and topography were combined with population maps to estimate the surgical burden. There was a large variability in accessibility at the subnational level.

Estimates from this study showed that approximately $93 \%$ of the all-age population in SSA lived within 2 hours of a major hospital that could theoretically carry out the bellwether procedures, reflecting trends of urbanisation in the region. Urban population in SSA varies between $60 \%$ and $80 \%$ in Angola, Botswana, Congo, South Africa; between $40 \%$ and $60 \%$ in DRC, Eritrea, Namibia, Somalia, Zambia and most Western and Central African countries; and between $20 \%$ and $40 \%$ in Sudan, Chad and most of Eastern African countries. At the same time, indeed, major hospitals are largely located in urban areas. $^{43}$ In most countries, more than $80 \%$ of children ( $<15$ years) were within 2 hours of a hospital, with the exception of Angola and Eritrea. Further, the proportion of population within $30 \mathrm{~min}$ in SSA reduced to $67 \%$ for all-age population and to $68 \%$ for children less than 15 years of age.

The burden for surgery, based solely on travel time estimation, in SSA was estimated between 115.3 million and 131.77 million in the 2-hour health facility catchments and was highest in densely populated countries like Nigeria, DRC, Ethiopia and Tanzania. The burden for all-age population and children under 15 years was lower in sparsely populated countries, including 


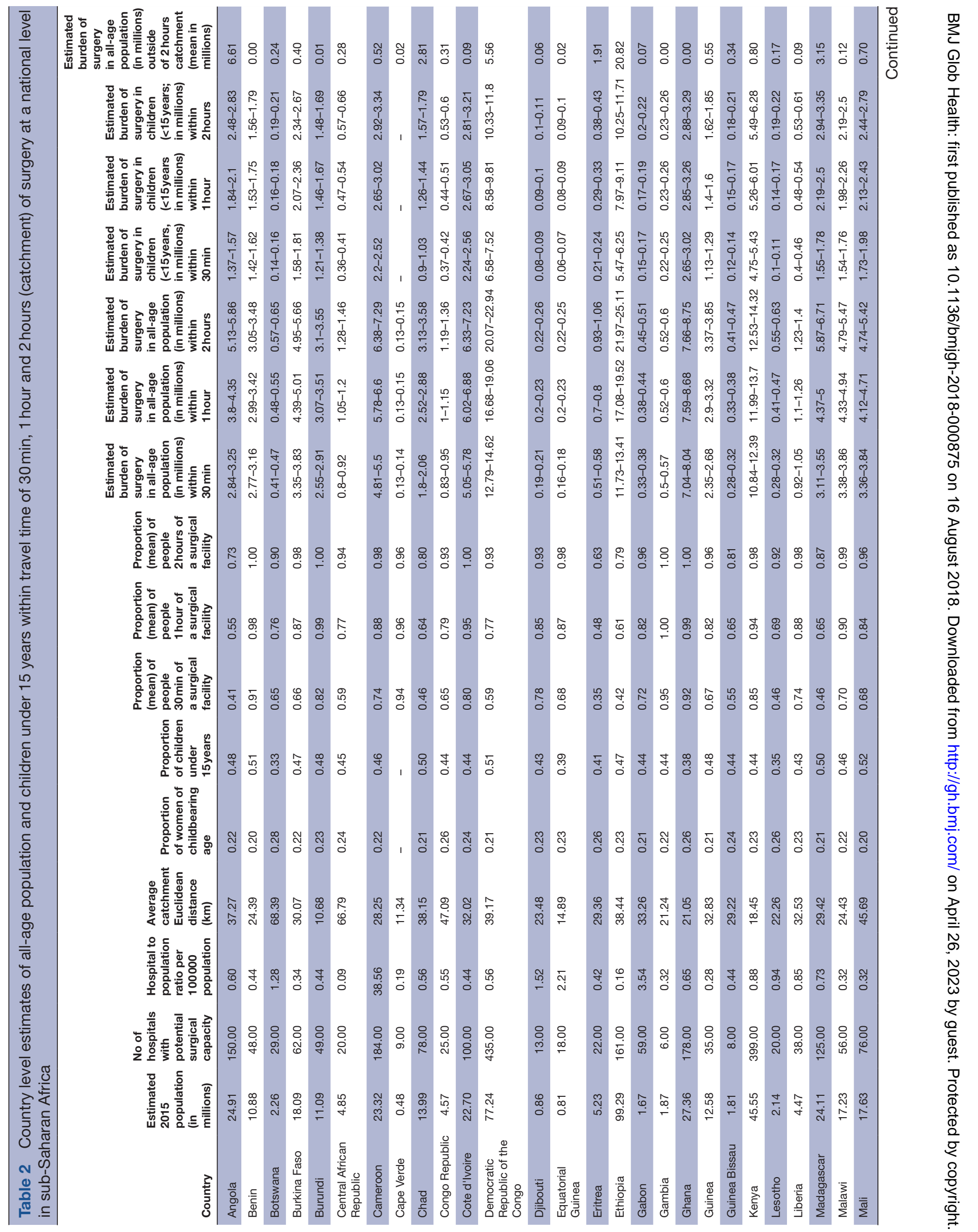




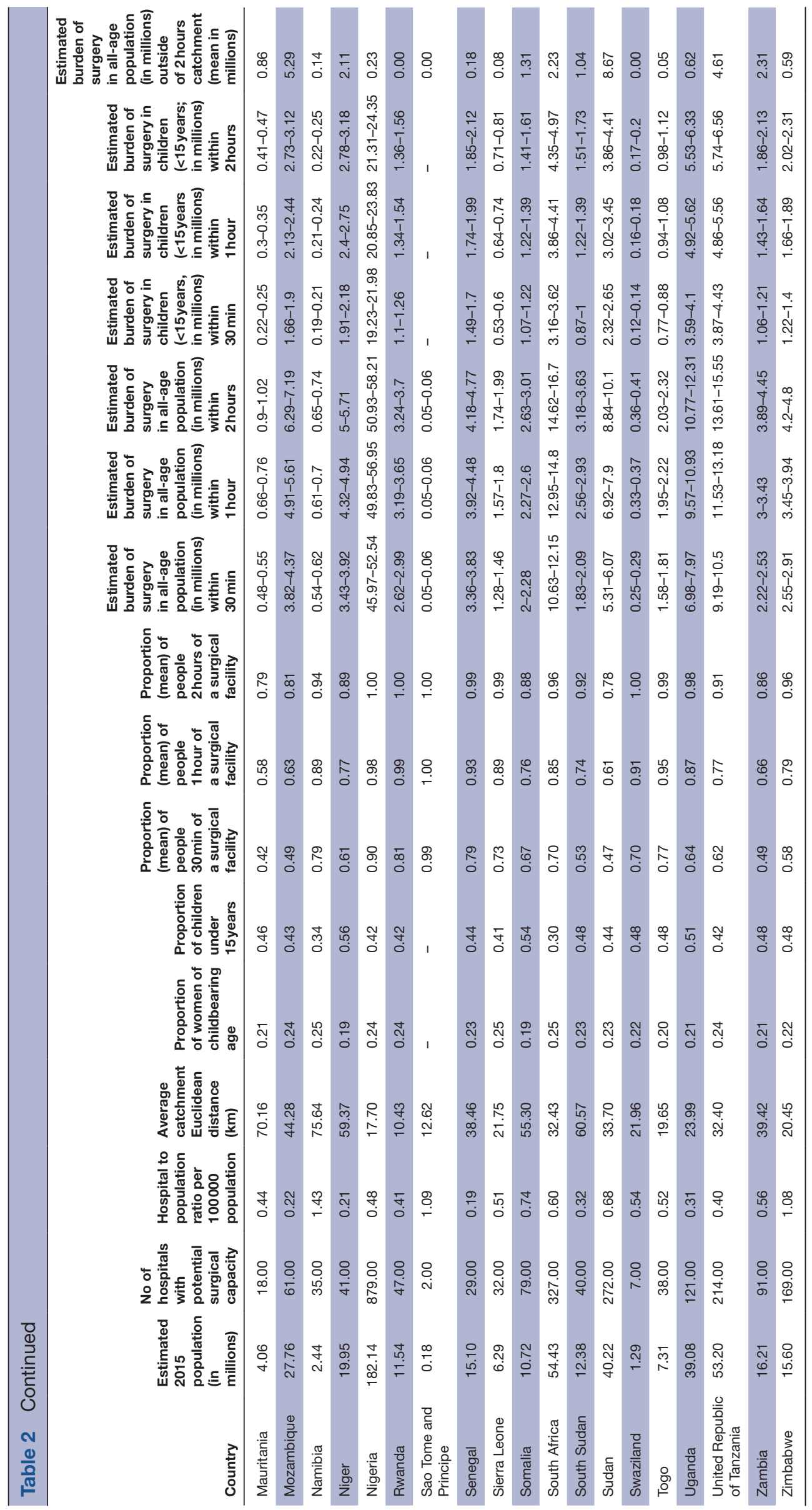




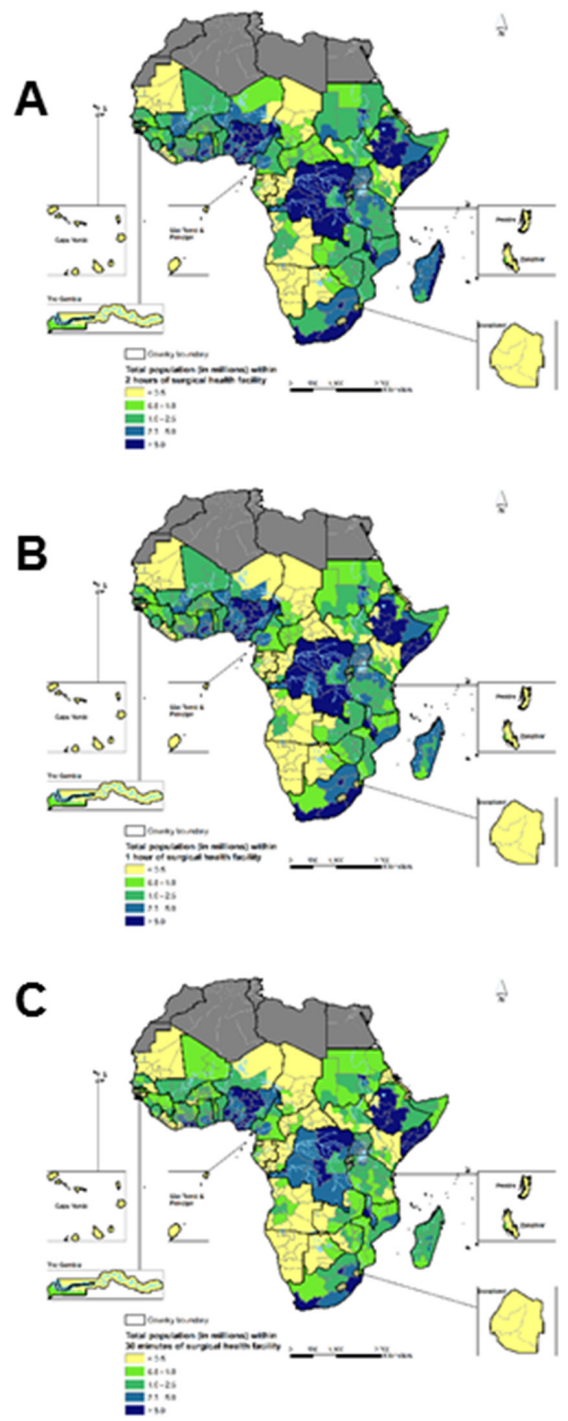

Figure 2 Population by administrative unit 1 in sub-Saharan Africa with access to major surgical facility.

Botswana, Djibouti, Equatorial Guinea and the islands of Cape Verde as well as Sao Tome and Principe. These estimates could be combined with the data on the remaining five indicators as well as other demographic and epidemiological data to provide for a comprehensive assessment of health system capacity to plan for the provision of timely and safe surgical care.

This study provides a first-level assessment of indicator 1 of the LCoGS on estimating the proportion of the population within 2 hours of a facility capable of providing the bellwether procedures. These estimates provide a foundation for estimating absolute access in SSA when hospital infrastructure is assessed based on surgical assessment modules. ${ }^{31}$ Health facility-level data on infrastructure, workforce and medicine are essential to providing true indicator 1 as defined by the LCoGS. ${ }^{1}$ They can also be useful for strategic planning and increase service provision.

A major assumption of our study was that major district hospitals could perform the three bellwether procedures, chosen to represent surgical capacity. Previous evidence from Zambia ${ }^{23}$ and Ghana ${ }^{30}$ suggest that only $17 \%$ and $23 \%$ of the major hospitals, respectively, have the capability to provide such basic essential safe surgery when infrastructural and human resource capacity were considered. A further assessment in East African countries suggested deficiencies in infrastructure and health worker training. ${ }^{21}$ Thus, a realistic view is that the true coverage rate of population for indicator 1 , controlling for infrastructural and human resource capacity, is much lower than that estimated here and only a few hospitals at a country level in SSA have the actual capacity to perform all the bellwether procedures based on reviews conducted in few countries in Africa. Therefore, further research must refine these findings with information on facility capacity to adequately and safely provide the bellwether procedures.

Travel times were derived by varying modes of travel and speeds based land use or land cover characteristics (eg, road, forest, bare land or urban areas), and topography (elevation). A basic assumption was that travel is multidirectional and influenced by the availability of roads. The results may, therefore, be biased because the actual travel patterns, access to motorised vehicles and accessibility for patients including the volume of referrals, road conditions (only motorway, primary or secondary roads) and speeds (using vehicles or motorcycles) are unknown. Empirical data for modelling these effects are not available for all countries in SSA, and future improvement on road quality data would impact calculation of travel times. Moreover, other financial, cultural and social factors, including costs, may impact the decision to go to the hospital, leading to bypassing phenomenon. ${ }^{44}$

There are other possible errors related to positional errors for hospital locations (up to $10 \mathrm{~m}$ for GPS georeferencing) or where address geocoding of place names were used as well as exclusion of private for hospitals. The estimation of access to surgery may be underestimated where private hospitals are often used compared with public-based hospitals. Further, a $1 \mathrm{~km}$ spatial resolution was adopted at country level for travel time estimation. This spatial resolution is probably not ideal for fine-scale mapping of the transport network and may overestimate access in remote rural areas or locations close to major roads. Mapping of road networks in Africa is not complete in all countries or better road data may exist for some countries but only for commercial purposes. There was also less control on the overall quality of other spatial ancillary data including elevation, complete mapping of all major roads and classification of land uses or land cover.

As a consequence, the need for essential surgery is expected to be much higher if all aspects of physical or geographic access, safety and financial risk protection are included in the definition of accessibility. This highlights the inadequacy of using a single metric for estimation of access to surgery. In general, the estimation of access to essential coverage requires a simultaneous assessment of 
human resource and infrastructure at the hospital level, which would require expanding hospital level assessments for each individual country, for example, through SPA implemented by the DHS with additional questions or a specific module on surgical procedures. ${ }^{21}$ The most recent SPA surveys include indicators on minor surgery or caesarean section at best. To date, they have been conducted in six countries: Namibia (2009 complete census of all health facilities, $\mathrm{n}=446),{ }^{45}$ Kenya $(2010$ sample of health facilities, $n=695),{ }^{46}$ Malawi $(2013-2014$ complete census of health facilities, $\mathrm{n}=977),{ }^{47}$ Senegal (2016 sample of health facilities, $\mathrm{n}=371){ }^{48}$ Tanzania (2014-2015 sample of health facilities, $n=1188)^{49}$ and Uganda (2007 sample of health facilities, $\mathrm{n}=491),{ }^{50}$ where data are not available in public domain.

Using a triangulation of hospitals data, geographic information systems and population data, this study estimated coverage at subnational levels for countries in SSA to provide a rapid assessment of geographic access. Although results suggest that all-age population within 2 hours was greater than $80 \%$ in most countries, it is observed that, with exception of small Island countries (eg, Mauritius, Seychelles, Cape Verde, Sao Tome and Principe, Equatorial Guinea), none of the sub-Saharan countries would meet the $80 \%$ and 2-hour threshold for actual safe and essential coverage on indicator 1 of the Lancet commission recommendation if surgical infrastructural and workforce differences are considered. For Sao Tome and Principe, for example, the main Island has one major public hospital whose population are within the 2-hour threshold (map not shown). Thus, while this may meet the threshold in terms of 2-hour geographic access, it is not known whether the main hospital has the capability to perform all bellwether procedures. This is also true for all the hospitals used in the study. There is, therefore, a need for future studies to explore the development of a hospital capacity index from national hospital surveys to scale coverage estimates developed here. That will also require continuous improvement in geolocation of hospital data surveys linked to health information systems.

Acknowledgements RWS is grateful to the UK's Department for International Development (DFID) for their continued support to a project Strengthening the Use of Data for Malaria Decision Making in Africa (DFID Programme Code no. 203155) that provided support to P00. P00 acknowledge support under the IDeAL Project (no. 107769). All authors acknowledge the support from the Wellcome Trust to the Kenya Major Overseas Programme (no. 203077).

Contributors SJ, VAA and AJT conceived and designed the study. SJ and VAA were responsible for data management, analysis and production of the first draft of manuscript. PNB, SJK, EAO, POO, JGM reviewed and edited drafts of the manuscript. All authors reviewed, edited and approved the final manuscript.

Funding AJT is supported by a Wellcome Trust Sustaining Health Grant (no. 106866/Z/15/Z) and Bill \& Melinda Gates Foundation (nos. OPP1106427, 1032350, OPP1134076). RWS is supported by the Wellcome Trust as Principal Research Fellow (no. 103602) that part supported POO.

Competing interests None declared.

Patient consent Not required.

Provenance and peer review Not commissioned; externally peer reviewed.
Data sharing statement A full database of hospital location data is available open access through the Harvard Dataverse under a CC-BY 4.0 license. All the ancillary spatial datasets and are available online.

Open access This is an open access article distributed in accordance with the Creative Commons Attribution Non Commercial (CC BY-NC 4.0) license, which permits others to distribute, remix, adapt, build upon this work non-commercially, and license their derivative works on different terms, provided the original work is properly cited, appropriate credit is given, any changes made indicated, and the use is non-commercial. See: http://creativecommons.org/licenses/by-nc/4.0/.

\section{REFERENCES}

1. Meara JG, Leather AJM, Hagander L, et al. Global Surgery 2030: evidence and solutions for achieving health, welfare, and economic development. The Lancet 2015;386:569-624.

2. Shrime MG, Bickler SW, Alkire BC, et al. Global burden of surgical disease: an estimation from the provider perspective. Lancet Glob Health 2015;3 Suppl 2:S8-9.

3. Rose J, Weiser TG, Hider P, et al. Estimated need for surgery worldwide based on prevalence of diseases: a modelling strategy for the WHO Global Health Estimate. Lancet Glob Health 2015;3 Suppl 2:S13-S20.

4. Shrime MG, Daniels KM, Meara JG. Half a billion surgical cases: Aligning surgical delivery with best-performing health systems. Surgery 2015;158:27-32.

5. Weiser TG, Haynes AB, Molina G, et al. Size and distribution of the global volume of surgery in 2012. Bull World Health Organ 2016;94:201-9.

6. Lozano R, Naghavi M, Foreman K, et al. Global and regional mortality from 235 causes of death for 20 age groups in 1990 and 2010: a systematic analysis for the Global Burden of Disease Study 2010. Lancet 2012;380:2095-128.

7. Huber B. Finding surgery's place on the global health agenda. Lancet 2015;385:1821-2.

8. Ozgediz D, Riviello R. The "other" neglected diseases in global public health: surgical conditions in sub-Saharan Africa. PLoS Med 2008;5:e121.

9. Luboga S, Macfarlane SB, von Schreeb J, et al. Bellagio Essential Surgery Group (BESG). Increasing access to surgical services in sub-saharan Africa: priorities for national and international agencies recommended by the Bellagio Essential Surgery Group. PLoS Med 2009;6:e1000200.

10. Chu K, Rosseel P, Gielis P, et al. Surgical task shifting in SubSaharan Africa. PLoS Med 2009;6:e1000078.

11. McQueen KA, Ozgediz D, Riviello R, et al. Essential surgery: Integral to the right to health. Health Hum Rights 2010;12:137-52.

12. Grimes CE, Henry JA, Maraka J, et al. Cost-effectiveness of surgery in low- and middle-income countries: a systematic review. World $\mathrm{J}$ Surg 2014;38:252-63.

13. Shrime MG, Alkire BC, Grimes C, et al. Cost-Effectiveness in Global Surgery: Pearls, Pitfalls, and a Checklist. World J Surg 2017;41:1401-13.

14. Holmer H, Shrime MG, Riesel JN, et al. Towards closing the gap of the global surgeon, anaesthesiologist, and obstetrician workforce: thresholds and projections towards 2030. Lancet 2015;385(Suppl 2):S40.

15. Holmer $\mathrm{H}$, Lantz A, Kunjumen $\mathrm{T}$, et al. Global distribution of surgeons, anaesthesiologists, and obstetricians. Lancet Glob Health 2015;3(Suppl 2):S9-11.

16. Anderson GA, Ilcisin L, Abesiga L, et al. Surgical volume and postoperative mortality rate at a referral hospital in Western Uganda: Measuring the Lancet Commission on Global Surgery indicators in low-resource settings. Surgery 2017;161:1710-9.

17. Shrime MG, Dare A, Alkire BC, et al. A global country-level comparison of the financial burden of surgery. Br J Surg 2016;103:1453-61.

18. Davies JF, Lenglet $A$, van Wijhe $M$, et al. Perioperative mortality: analysis of 3 years of operative data across 7 general surgical projects of Médecins Sans Frontières in Democratic Republic of Congo, Central African Republic, and South Sudan. Surgery 2016;159:1269-78.

19. Rickard JL, Ntakiyiruta G, Chu KM. Associations with perioperative mortality rate at a major referral hospital in Rwanda. World J Surg 2016;40:784-90.

20. Alkire BC, Raykar NP, Shrime MG, et al. Global access to surgical care: a modelling study. Lancet Glob Health 2015;3:e316-23.

21. Hsia RY, Mbembati NA, Macfarlane S, et al. Access to emergency and surgical care in sub-Saharan Africa: the infrastructure gap. Health Policy Plan 2012;27:234-44. 
22. Hofman JJ, Dzimadzi C, Lungu K, et al. Motorcycle ambulances for referral of obstetric emergencies in rural Malawi: do they reduce delay and what do they cost? Int J Gynaecol Obstet 2008;102:191-7.

23. Esquivel MM, Uribe-Leitz T, Makasa E, et al. Mapping disparities in access to safe, timely, and essential surgical care in Zambia. JAMA Surg 2016;151:1064-9.

24. World Health Organization. WHO Guidelines for Safe Surgery. 2009 http://apps.who.int/iris/bitstream/10665/44185/1/9789241598552 eng.pdf (accessed Oct 2017).

25. Tansley G, Schuurman N, Amram O, et al. Spatial access to emergency services in low- and middle-income countries: a GISbased analysis. PLoS One 2015;10:e0141113.

26. Engjom HM, Morken NH, Norheim OF, et al. Availability and access in modern obstetric care: a retrospective population-based study. BJOG 2014;121:290-9.

27. Ouma PO, Maina J, Thuranira PN, et al. Access to emergency hospital care provided by the public sector in sub-Saharan Africa in 2015: a geocoded inventory and spatial analysis. Lancet Glob Health 2018;6:e342-e350.

28. Ouma P, Maina J, Thuranira P, et al. Access to emergency hospital care provided by the public sector in sub-Saharan Africa. The Lancet Global health. In Press. 2017.

29. Ouma P, Okiro EA, Snow RW. Sub-Saharan Public Hospitals Geocoded database: Harvard Dataverse, 2018.

30. Stewart BT, Tansley G, Gyedu A, et al. Mapping population-leve spatial access to essential surgical care in Ghana using availability of Bellwether procedures. JAMA Surg 2016;151:e161239-e39.

31. WHO. WHO Integrated Management for Emergency and Essential Surgical Care (IMEESC) toolkit: World Health Organization. 2017 www.who.int/surgery.

32. Google. Google Earth: Google Inc. 2010 http://www.google.co.uk/ intl/en_uk/earth/ (accessed 06 Jun 2010).

33. ESA. GlobCover 2009 (Global Land Cover Map). 2010 http://ionia1. esrin.esa.int/ (accessed January 15 2011).

34. Worldpop. The WorldPop project. 2016 http://www.worldpop.org.uk/ (accessed 01 Nov 2016).

35. Stevens FR, Gaughan AE, Linard C, et al. Disaggregating census data for population mapping using random forests with remotelysensed and ancillary data. PLoS One 2015;10:e0107042.

36. Ray N, Ebener S. AccessMod 3.0: computing geographic coverage and accessibility to health care services using anisotropic movement of patients. Int J Health Geogr 2008;7:63.

37. Macharia PM, Odera PA, Snow RW, et al. Spatial models for the rational allocation of routinely distributed bed nets to public health facilities in Western Kenya. Malar J 2017;16:367.
38. Manongi R, Mtei F, Mtove G, et al. Inpatient child mortality by travel time to hospital in a rural area of Tanzania. Trop Med Int Health 2014;19:555-62.

39. Bennett A, Yukich J, Miller JM, et al. A methodological framework for the improved use of routine health system data to evaluate national malaria control programs: evidence from Zambia. Popul Health Metr 2014;12:1-11.

40. Tobler W. Three presentations on geographical analysis and modeling: National Center for Geographic Information and Analysis. Santa Barbara, CA93106-4060: University of California, Santa Barbara, 1993.

41. Kelly C, Hulme C, Farragher $\mathrm{T}$, et al. Are differences in travel time or distance to healthcare for adults in global north countries associated with an impact on health outcomes? A systematic review. BMJ Open 2016;6:e013059.

42. Rossaint R, Bouillon B, Cerny V, et al. Management of bleeding following major trauma: an updated European guideline. Crit Care 2010;14:R52.

43. United Nations, Department of Economic and Social Affairs Population Division. World urbanization prospects, 2018.

44. Alford-Teaster J, Lange JM, Hubbard RA, et al. Is the closest facility the one actually used? An assessment of travel time estimation based on mammography facilities. Int J Health Geogr 2016;15:8.

45. Ministry of Health and Social Services (MoHSS), ICF Macro. Namibia Health Facility Census (HFC). Windhoek, Namibia, 20092010.

46. Population NCAf, Development - NCAPD/Kenya, Ministry of Medical Services - MOMS/Kenya. Kenya service provision assessment survey 2010. Nairobi, Kenya: NCAPD/Kenya, MOMS/Kenya MOPHS/Kenya, KNBS, ICF Macro, 2011.

47. Ministry of Health - MoH/Malawi, ICF International. Malawi service provision assessment 2013-14. Lilongwe, Malawi: MoH/Malawi and ICF International, 2014.

48. Agence Nationale de la Statistique et de la Démographie - ANSD/ Senegal, Ministère de la Santé et de l'Action Sociale, ICF. Sénégal Enquête Continue sur la Prestation des Services de Soins de Santé (ECPSS) 2016. Rockville, Maryland, USA: ANSD/Sénégal and ICF, 2017.

49. Health Mo, Social Welfare/Tanzania, Ministry of Health/Zanzibar. Tanzania service provision assessment survey 2014-2015. Dar es Salaam, Tanzania: MoHSW/Tanzania, MoH/Tanzania, NBS/Tanzania, OCGS/Tanzania, and ICF International, 2016.

50. Ministry of Health/Uganda, Macro International. Uganda service provision assessment survey 2007. Kampala, Uganda: Ministry of Health/Uganda and Macro International, 2008. 